\title{
MONITORING THE EFFICACY OF SPECIFIC TREATMENT IN CHRONIC CHAGAS DISEASE BY POLYMERASE CHAIN REACTION AND FLOW CYTOMETRY ANALYSIS
}

\author{
SÁNCHEZ G.*, CORONADO X.***, ZULANTAY I.**, APT W.**, GAJARDO M.***, SOLARI S.* \& VENEGAS J.**
}

\section{Summary :}

PCR and FC-ALTA were used to monitor parasite clearance in 54 chronic chagasic patients who had completed therapy with allopurinol (ALLO, $n=31$ ) or itraconazole (ITRA, $n=23$ ) ten years earlier. All patients maintained positive conventional serology. 25 of them showed positive XD (ALLO, $n=11$ and ITRA, $n=14$ ) and 29 negative XD (ALLO, $n=20$ and ITRA, $n=9$ ). 43 patients were positive by both techniques (ALLO, $n=23$ and ITRA, $n=20$ ). Seven of 54 patients were negative by PCR and positive by FC-ALTA and three of 54 were positive by PCR and negative by FC-ALTA. Only one case with both tests negative should be considered cured. Of 29 patients with negative XD, 14 treated ALLO (70 \%) and nine with ITRA $(77.8 \%)$ showed positive PCR and FC-ALTA. These results do not show differences of efficacy among the drugs, and reinforce the relevance of using sensitive tools such as PCR and FC-ALTA for the follow-up of patients with chronic Chagas disease.

KEY WORDS : chronic Chagas disease, polymerase chain reaction (PCR), flow cytometry anti-live trypomastigote antibodies (FC-ALTA)

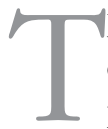
he disparity in trypanocidal action of available drugs as well as their negative side effects have prompted a search for new compounds with low toxicity and increased efficacy during the chronic phase of Chagas disease (Rodríguez et al., 2002). One of the major challenges regarding the evaluation of treatment effectiveness is the lack of reliable laboratorial approaches for use as tools for cure criteria (Chiari, 1999). Two categories of tests are available, including serological and parasitological methods. Parasitological tests are based on parasite demonstration by hemoculture, xenodiagnosis, or a parasitological molecular test (PCR), whereas serological methods evaluate the presence of specific antibodies by immunological

\footnotetext{
* Laboratorio Biología Molecular de Parásitos y ** Laboratorio de Parasitología Básico-Clínico, Programa de Biología Celular y Molecular, Instituto de Ciencias Biomédicas. Facultad de Medicina.

**:* Departamento de Patología, Facultad de Odontología. Universidad de Chile.

Correspondence: Gittith Sánchez, Programa de Biología Celular y Molecular, Instituto de Ciencias Biomédicas. Facultad de Medicina. Universidad de Chile. Casilla 70086, Santiago 7, Chile.

Tel.: + 56-2-6786757 - Fax: + 56-2-735-5580.

E-mail: gsanchez@med.uchile.cl
}

Résumé : Évaluation de L'EFFICACITÉ DE TRAITEMENTS SPÉCIFIQUES DE LA Maladie De Chagas par PCR ET CyTOMÉtRie DE FluX La PCR et la cytométrie de flux (FC-ALTA) ont été employées pour vérifier la guérison de 54 patients infectés par Trypanosoma cruzi et traités par l'allopurinol (ALLO) ou l'itraconazole (ITRA) 10 ans auparavant. Ces patients ont toujours présenté une sérologie positive. 25 d'entre eux ont un xénodiagnostic (XD) toujours positif (ALLO, $n=11$ et ITRA, $n=14$ ) et 29 un xénodiagnostic négatif (ALLO, $n=20$ et ITRA, $n=9$ ). 43 patients sont positifs par PCR et FC-ALTA (ALLO, $n=23$ et ITRA $n=20$ ). Sept sur 54 sont négatifs en PCR et positifs par FC-ALTA alors que trois sont positifs en PCR et négatifs en FC-ALTA. Un seul cas avec les deux tests négatifs peut être considéré comme guéri. Parmi les 29 patients avec un xénodiagnostic négatif, 14 AlLO et neuf ITRA ont une PCR et un FC-ALTA positif. Les résultats n'ont pas montré de différences d'efficacité entre les deux traitements et renforcent l'intérêt de méthodes diagnostiques sensibles comme la PCR ou le FC-ALTA pour le suivi des patients avec une maladie de Chagas chronique.

MOTS CLÉS : maladie de Chagas, PCR, cyłométrie de flux.

methods, such as indirect hemagglutination (IHA), indirect immunofluorescence assay (IFA), and enzymelinked immunosorbent assay (ELISA) (Chiari, 1999; de Castro et al., 2002). It has always been difficult to evaluate the incidence of cure in chronic chagasic patients who have received anti-parasitic treatment by serology, since a humoral response against T. cruzi antigens may remain for years even in the absence of the parasite (Galvao et al., 1993). Antibodies present in the serum of chagasic patients induce lysis in trypomastigote forms in the presence of complement (CoML), indicating the presence of active infection (Galvao et al., 1993; Sánchez et al., 1995). Following specific treatment, lytic antibodies disappear from the serum of some patients while conventional serology remains positive. Another approach for investigating and monitoring the efficacy of specific chemotherapy is the analysis by flow cytometry of anti-live trypomastigote antibodies (FC-ALTA) (Martins-Filho et al., 1995; 2002). The validation of the technique was performed with serum samples from treated and non-treated patients who were classified according CoML results, demonstrating a high correlation between the techniques. Also, the polymerase chain reaction (PCR), has been 
used to detect T. cruzi in the blood of chronic chagasic patients (Britto et al., 1995, 2001; Solari et al., 2001).

Recently, a strong correlation was reported between positive PCR and the presence of lytic antibodies among chagasic patients, suggesting that PCR could be effective in evaluating parasitological cure in patients who received a specific treatment (Zulantay et al., 2004). The present work reports the usefulness of PCR and FCALTA to monitor parasite clearance in 54 chronic chagasic patients who had completed a therapeutic program with allopurinol (ALLO, $\mathrm{n}=31$ ) or itraconazole (ITRA, $\mathrm{n}=23$ ), ten years earlier, using PCR and FC-ALTA. All patients maintained positive conventional serology and 29 of them $(53.7 \%)$, presented negative XD results.

\section{MATERIAL AND METHODS}

\section{PATIENTS}

4 chronic chagasic individuals, 25 female and 29 male (mean 22 years old) from an area of Chile (Regions IV and V) where the disease is highly endemic were treated with allopurinol (ALLO) or itraconazole (ITRA) in 1992 (Apt et al., 2003). Patients came from regions that are under epidemiological surveillance by the Vector Control Program of the Ministry of Health and the Initiative of Southern Cone Initiative (WHO, 2000). All patients maintained positive conventional serology ten years after therapy as determined by two methods, Indirect Immunofluorescence (IFI) and ELISA. The results of in the IFI test and de ELISA test for Chagas disease (BIOSChile, Ingenieria Genética, S.A.) were considered positive when the serum title was grater than 1:20 and the cut-off value was at least two standard deviations above the mean optic density of the negative control serum, respectively.

\section{CHEMOTHERAPY PROTOCOL}

Chagasic patients were selected from a randomized, double-blind study to evaluate the efficacy and tolerance of allopurinol ( $\mathrm{n}=31 ; 8.5 \mathrm{mg} / \mathrm{Kg} /$ for 60 days in $300 \mathrm{mg}$ tablets; Urogotan ${ }^{\circledR}$, Silesia Laboratories, Chile) at a daily dose of itraconazole $(\mathrm{n}=23 ; 6 \mathrm{mg} / \mathrm{Kg} /$ day in $100 \mathrm{mg}$ capsules; Sporanox $^{\circledR}$, Janssen Laboratories, Beerse, Belgium) administered as directly observed therapy (DOT) divided in two doses over a 120-day period. The study was approved by the Ethics Committee of the Faculty of Medicine of the University of Chile, and informed consent was obtained from each patient (Apt et al., 2003).

\section{XENODIAGNOSIS}

The XD test was carried out simultaneously with the blood sampling for PCR using two cylindrical wooden vials (seven third-instar of Triatoma infestans each). After applying the test XD to patients, a microscopic examination of insect faeces was performed at 30, 60, or 90 days (when ever previous examination was negative). All of the microscopic fields in a $2.2 \mathrm{~cm}$ area were examined twice (Schenone, 1999).

\section{PARASITE}

Tissue culture-derived trypomastigotes from Vero cells maintained in RPMI 1640 medium supplemented with $10 \%$ fetal bovine serum (Gibco, Grand Island, NY) at $37^{\circ} \mathrm{C}$ in an atmosphere of $5 \% \mathrm{CO}_{2}$ were used. Parasites were collected five days post infection from the supernatant fraction. MF T. cruzi strain was isolated in our laboratory from a chronic case of Chagas disease of the metropolitan region of Santiago and was classified as zymodeme 1 (Wallace, 2001).

\section{FC-ALTA}

The immnunofluorescence reaction was performed as described by Martins-Filho et al. (2000). Briefly, live trypomastigotes $\left(5 \times 10^{5}\right)$, were incubated at $37^{\circ} \mathrm{C}$ by $30 \mathrm{~min}$ in the presence of a 1:256 final dilution of serum. After incubation with serum parasites were washed once with $0.15 \mathrm{M}$ pH $7.2 \mathrm{PBS}$ containing $10 \%$ FBS. Parasite suspensions were reincubated at $37^{\circ} \mathrm{C}$ for $30 \mathrm{~min}$ in the dark in the presence of fluorescein isothiocyanate (FITC)-conjugated anti-human IgG antibody (Beckton \& Dickinson) diluted 1:400 in PBS-10 \% FBS and then parasites were washed with PBS-10\% FBS. Flow cytometry measurements were performed on a FACScan equipped with CellQuest software (BD Biosciences San Diego, CA) interfaced to an Apple Quadra FACStation. An average of 10,000 gated trypomastigotes were analysed for relative fluorescence intensity by using a single FITC histogram for each individual sample. Data analysis was performed by establishing $20 \%$ of the relative percentage of positive fluorescent parasites (PPFP) as the cut-off between negative and positive results as described by Martins-Filho et al. (1995). Positive controls included serum from nontreated chagasic patients, whereas samples from uninfected individuals were included as negative controls.

\section{VIABILITY OF PARASITES}

Incorporation of propidium iodide (PI) was used to asses the amount of dead cells since this stain enter only to dead cells (red fluorescence). PI was added to tubes containing $5 \times 10^{5}$ alive trypomastigotes at $1 \mu \mathrm{g} / \mathrm{ml}$ final concentration before flow cytometry analyses.

\section{PCR}

Two ml of blood was mixed with the same volume of a $6 \mathrm{M}$ guanidine hydrochloride, $200 \mathrm{mM}$ EDTA solu- 
tion, boiled for $15 \mathrm{~min}$ and stored at $4^{\circ} \mathrm{C}$. DNA was extracted from $500 \mu \mathrm{l}$ of the mixture using the phenolchloroform protocol and precipitated with ethanol as described by Wincker et al. (1994). DNA was resuspended in $50 \mu$ of water, chromatographed in a P10 filtration microcolumn and stored at $-20^{\circ} \mathrm{C}$. PCR reactions were performed as described by Solari et al. (2001). Briefly, $5 \mu$ of template DNA was amplified in a final volume of $50 \mu \mathrm{l}$ containing $0.25 \mathrm{mM}$ of each dATP, dCTP, dGTP and dTTP, $200 \mathrm{ng}$ of forward and reverse $T$. cruzi specific primers 121 (5'-AAATAATGTACGGG (T/G) GAGATGCATGA3') and 122 (5' GGTTCGATTGGGGTTGGTGTAATATA3'), 2.5 U of Taq polymerase, $5 \mu \mathrm{l}$ of $10 \times$ Taq DNA polymerase buffer and $6.7 \mathrm{mM} \mathrm{MgCl}_{2}$. Mineral oil (80 $\left.\mu \mathrm{l}\right)$ was added to avoid reaction mixture evaporation. The PCR condition was performed to ensure that all fragments were completely synthesized. Two cycles at $98^{\circ} \mathrm{C}$ for one min and $64^{\circ} \mathrm{C}$ for two $\mathrm{min}, 33$ cycles at $94^{\circ} \mathrm{C}$ for one min and $64^{\circ} \mathrm{C}$ for one $\mathrm{min}$; a final incubation at $72^{\circ} \mathrm{C}$ for $10 \mathrm{~min}$ in a thermocycler. Routinely, total kinetoplast of T. cruzi was included as a positive control. A 330-bp product represented a positive assay and all PCR assays were performed in duplicate. PCR products were fractionated by electrophoresis in $2 \%$ agarose gels, stained with ethidium bromide and visualized under an ultraviolet light. A similar protocol was used as PCR internal control for amplification of the human $\beta$-globin gene sequences as described (Saiki, 1985).

\section{STATISTICS}

All results were analyzed using comparison of differentiation of percentages $(Z)$. Values with $p<0.05$ were considered to be significant.

\section{RESULTS}

r n the present work, 54 chronic chagasic patients with positive conventional serology, 29 of them (54\%) with negative XD ten years after finishing chemotherapy with ALLO or ITRA, were evaluated by PCR and FC-ALTA (Table I). T. cruzi DNA detection was considered positive when a band of 330 bp from PCR was observed (Fig. 1). The results of flow cytometry were expressed as the percentage of positive fluorescent parasites (PPFP) for each individual sample, establishing $20 \%$ PPFP as the cut-off between negative and positive results.

Our results show that 43 of 54 cases were positive by both PCR and FC-ALTA. Ten cases showed dissociated

\begin{tabular}{|c|c|c|c|c|c|c|c|c|c|c|}
\hline \multirow[b]{2}{*}{ No. of cases } & \multirow[b]{2}{*}{ Drug } & \multirow[b]{2}{*}{$\mathbf{X D}$} & \multicolumn{2}{|c|}{ PCR + FC-ALTA + } & \multicolumn{2}{|c|}{ PCR + FC-ALTA- } & \multicolumn{2}{|c|}{ PCR-FC-ALTA + } & \multicolumn{2}{|c|}{ PCR-FC-ALTA- } \\
\hline & & & $\mathbf{n}$ & $(\%)$ & $\mathbf{n}$ & $(\%)$ & $\mathbf{n}$ & $(\%)$ & $\mathbf{n}$ & $(\%)$ \\
\hline 11 & ALLO & Positive & $9^{*}$ & (81.8) & 2 & (18.2) & 0 & & 0 & \\
\hline 20 & ALLO & Negative & $14^{* * *}$ & $(70)$ & 0 & & 5 & (25) & 1 & (5) \\
\hline 14 & ITRA & Positive & $13^{*}$ & (92.9) & 1 & $(7.1)$ & 0 & & 0 & \\
\hline 9 & ITRA & Negative & $7^{* * *}$ & (77.8) & 0 & & 2 & (22.2) & 0 & \\
\hline Total 54 & & & 43 & (79.6) & 3 & (5.6) & 7 & (13) & 1 & (1.9) \\
\hline
\end{tabular}

* Comparison PCR(+) FC-ALTA(+) XD(+) ALLO versus PCR(+) FC-ALTA(+) XD(+) ITRA, p = 0.19766 NS.

*: Comparison PCR (+) FC-ALTA(+) XD(-) ALLO versus PCR (+) FC-ALTA (+) XD(-) ITRA, p $=0.29906$ NS.

Table I. - PCR and FC-ALTA in chronic chagasic patients with positive or negative xenodiagnosis, ten years after treatment with allopurinol or itraconazole.

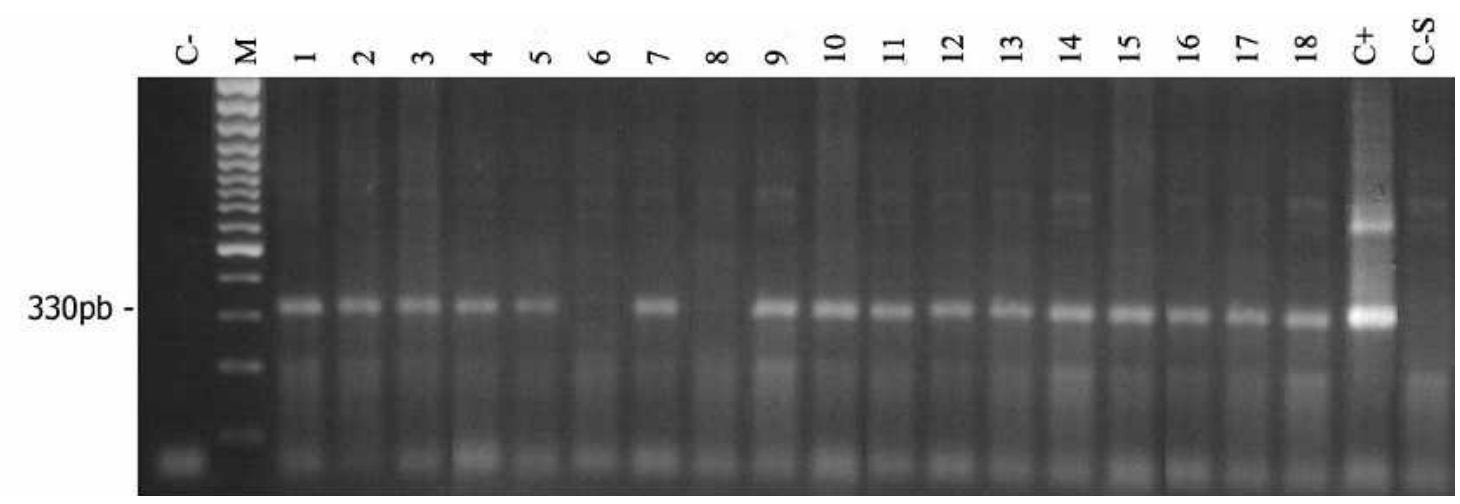

Fig. 1. - Electrophoretic pattern of the 330 bp minicircle region of T. cruzi kDNA-PCR amplified with primers 121 and 122 from different human subjects and stained with ethidium bromide.

Lane $\mathrm{M}$ is a $100 \mathrm{bp}$ ladder as a molecular size marker. Lane C- is a sample from a negative control. Lanes 1 to 18 show patients with a positive or negative PCR-based diagnosis. Lane $\mathrm{C}+$ is a sample from a positive control. Lane C-S is a negative blood sample control. 
results: three cases with positive PCR and negative FCALTA (two treated with ALLO and one with ITRA), seven cases with negative PCR and positive FC-ALTA (five treated with ALLO and two with ITRA). As can be observed, in Table I, cases with positive PCR and positive FC-ALTA $(79.6 \%)$, had similar percentages when the patients were treated with ALLO (74.2\%) or ITRA $(86.9 \%)(p=0.12507$, NS). Only one case showed negative results with XD, PCR and FC-ALTA and could be considered cured. Patients whose XD post-treatment were positive $(n=25)$, showed highly concordant positive results with PCR (100\%) and FC-ALTA (88 \%). This fact was similarly observed in patients treated with ALLO (81.8 \%) or ITRA (92.9\%) ( $p=0.19766$, NS). Also, in the group of patients with negative $\mathrm{XD}$, concordant positive results with PCR and FC-ALTA were observed in the groups treated with ALLO (70 \%) and with ITRA $(77.8 \%)(p=0.29906$, NS). Seven out 29 cases $(24.1 \%)$ were considered as "dissociated" (negative PCR and positive FC-ALTA) and all of them belonged to the group with negative $\mathrm{XD}$. In contrast the three "dissociated" cases with positive PCR and negative FC-ALTA belonged to the group with positive XD.

\section{DISCUSSION}

The establishment of a cure criterion in chronic phase of Chagas disease following a specific treatment remains unresolved. The CoML test has been a useful tool in establishing the existence of an active ongoing infection. After specific treatment some patients are regularly negative in CoML assays but only as small percentage of treated patients present negative results in conventional serology antibodies (CSA) detection (Galvao et al., 1993; Sánchez et al., 1995; Zulantay et al., 2004). In considering the technical laboriousness of CoML, Martins-Filho (2002) proposed an alternative tool (FC-ALTA) that was demonstrated to be comparable to CoML for monitoring the treatment effectiveness in cases of human Chagas disease.

Parasitological tests such as hemoculture or xenodiagnosis have proven to be highly specific, but the sensitivity of these techniques is low. Recently, molecular assays by PCR, which amplify certain repetitive sequences of trypanosome kDNA have been proposed as a good alternative tool for detection of T. cruzi in human blood (Britto et al., 1995; Chiari, 1999; Zulantay et al., 2004). The $330 \mathrm{bp}$ fragment of the kinetoplast minicircles is normally used as a target for amplification. The PCR assays have shown a variable degree of efficiency, thus a negative result does not necessarily mean that the individual is free of infection because the volume of sample can be insufficient (Solari, 2001). Chiari (1999), reported that an optimized PCR protocol is well correlated with detection of antibodies that induce lysis in trypomastigote forms (CoML) in the presence of complement, indicating active infection in those patients. Until now, there are no reports using both, PCR and flow cytometry analysis of anti-live trypomastigote antibodies in the assessment of treatment efficacy.

The present study is a 10 years follow-up of 54 chronic chagasic patients, after finishing treatment with ALLO or ITRA. Notably, seven cases with negative XD and PCR showed positive FC-ALTA, indicative of ongoing infection. The three dissociated cases with positive XD, positive PCR and negative FC-ALTA can be due to decrease of immunity in these patients, that produce low level of anti-live trypomastigotes, unable to be detected in the tested serum dilution (1:256). Under the criteria used in this work, only one patient was negative by PCR and FC-ALTA and can be considered as cured. However, drugs can cause beneficial clinical effect by decreasing parasitic load, not necessarily associated with the eradication of parasites. Therefore, efficiency of treatment must be evaluated not only by negativity of $T$. cruzi detection tests but also by beneficial clinic effect as regression and prevention of electrocardiographic abnormalities observed in treated patients (Apt et al., 2003). For this reason, ITRA is been using by our group to treat patients with chronic Chagas disease.

Our results show that FC-ALTA should be indicated to confirm cure, especially in cases of individuals with several negative parasitological tests or when discordant results with different techniques are obtained. Our results show that in the group of patients with negative XD, concordant positive results with PCR and FCALTA were observed both, in the group treated with ALLO (70 \%) and with ITRA (77.8\%) demonstrating the high sensitivity of these tools compared with XD. In conclusion, both techniques used in the present study proved to be complementary in evaluating the efficacy of treatment in chronic chagasic patients.

\section{ACKNOWLEDGEMENTS}

'T This work was supported by grants DI-SAL 03/ 06-2, Fondecyt 1040731 and Postgraduate Departament fellowship PG/83/2003, University of Chile.

\section{REFERENCES}

Apt W., Arribada A.., Zulantay I., SÁnchez G., Vargas S.L. \& RODRÍGUEZ J. Itraconazole or allopurinol in the treatment of chronic American trypanosomiasis: the regression and prevention of electrocardiographic abnormalities during nine years of follow-up. Annals of Tropical Medicine and Parasitology, 2003, 97, 23-29. 
Britto C., Cardoso M.A., Monteiro Van C.M., HasslocherMoreno A., Xavier S.S., Oeleman W., Santoro A., Pirmez C., Morel C. \& Wincker P. Polymerase chain reaction detection of Trypanosoma cruzi in human blood samples for diagnosis and treatment evaluation. Parasitology, 1995, $110,241-247$.

Britto C., Silveira C., Cardoso M.A., Marques P., Luquetti A., Macedo V. \& Fernández O. Parasite persistence in treated chagasic patients revealed by xenodiagnosis and polymerase chain reaction. Memórias Instituto Oswaldo Cruz, 2001, 96, 823-826.

ChIARI E. Chagas disease diagnosis using polimerase chain reaction, hemoculture and serologic methods. Memórias Instituto Oswaldo Cruz, 1999, 94 (Suppl.), 299-300.

de Castro A.M., Luquetti A.O., Rassi A., Rassi G.G., Chiari E. \& GALVAO L.M.C. Blood culture and polymerase chain reaction for the diagnosis of the chronic phase of human infection with Trypanosoma cruzi. Parasitology Research, 2002, 88, 894-900.

Galvao L.M., Nunes R.M., Cancado J.R., Brener Z. \& Krettli A.U. Lytic antibody title as a means of assessing cure alter treatment of Chagas disease: a 10 years follow-up study. Transactions of the Royal Society of Tropical Medicine and Hygiene, 1993, 87, 220-223.

Martins-Filho O., Pereira M.E.S., Carvalho J.F., Cancado J.R., RAssi A. \& BRENer Z. Flow cytometry: a new approach to detect anti-live trypomastigote antibodies and monitor the efficacy of specific treatment in human Chagas disease. Clinical and Diagnostic Laboratory Immunology, 1995, 5, 569573.

Martins-Filho O., Eloi-Santos S.M., Teixeira A., Correa R., Rassi A., Ostemayer A., Rassi G.G. \& Brener Z. Double-blind study to evaluate flow cytometry analysis of anti-live trypomastigote antibodies for monitoring treatment efficacy in cases of human Chagas' disease. Clinical and Diagnostic Laboratory Immunology, 2002, 5, 1107-1113.

Rodríguez Coura J. \& DE CASTRO S.L. A critical Review on Chagas disease Chemotherapy. Memórias Instituto Oswaldo Cruz, 2002, 97, 3-24.

Saiki R.K., Scharf S., Faloona F., Mullis KB., Horn GT., Erlich HA. \& ARnheim N. Enzymatic amplification of $\beta$-globin sequences and restriction site analyses for diagnosis of sickle cell anemia. Science, 1985, 230, 1350-1354.

Sánchez G., Zulantay I., Venegas J., Solari A., Gálvez R., Peña P., Rodríguez J. \& APT W. Treatment with allopurinol and itraconazol changes lytic activity in patients with chronic, low grade Trypanosoma cruzi infection. Transactions of the Royal Society of Tropical Medicine and Hygiene, 1995, 89, 438-439.

SChenone H. Xenodiagnosis. Memórias Instituto Oswaldo Cruz, 1999, 94, 289-294.

Solari A., Ortiz S., Soto A., Arancibia C., Campillay R., Contreras M., Salinas P., Rojas A. \& Schenone H. Treatment of Trypanosoma cruzi-infected children with nifurtimox: a three year follow-up by PCR. Journal of Antimicrobial Chemotherapy, 2001, 48, 515-519.

Wallace A., Ortiz S., Sanchez G., Villagra R., Muga M. \& SOLARI A. Studies on parasitemia courses and mortality in mice infected with genetically distant Trypanosoma cruzi clonets. Biological Research, 2001, 34 (2), 83-90.

World Health Organization. Chagas disease interrupted in Chile. TDR News, 2000, 61, 10.

Wincker P., Bosseno N.F., BritTo C., Yaksic N., Cardoso N.A., Morel C.M. \& Breniere S.F. High correlation between Chagas disease serology and PCR-based detection of Trypanosoma cruzi kinetoplast DNA in Bolivian children living in a edemic area. FEMS. Microbiology Letters, 1994, 124, 419-424.

Zulantay I., Honores P., Solari A., Apt W., Ortiz S., Osuna A., RojAs A., LÓPEZ B. \& SÁNCHEZ G. Use of polymerase chain reaction (PCR) and hybridization assays to detect Trypanosoma cruzi in chronic chagasic patients treated with itraconazole or allopurinol. Diagnostic Microbiology and Infectious Disease, 2004, 48, 253-257.

Reçu le 17 mai 2005 Accepté le 4 juillet 2005 